\title{
Gawai Dayak Festival and the Increase of Foreign Tourist Visits
}

\author{
Festival Gawai Dayak dan Peningkatan \\ Kunjungan Wisatawan Mancanegara
}

\author{
Elyta \\ Universitas Tanjungpura Pontianak
}

\begin{abstract}
ABSTRAK
Gawai Dayak adalah festival tahunan di Kalimantan Barat, Indonesia dan Sarawak, Malaysia, yang memperlihatkan kekayaan seni budaya dan tradisi Suku Dayak yang berkembang baik di Kalimantan Barat maupun di Sarawak. Artikel ini mengkaji upaya yang dilakukan pemerintah Provinsi Kalimantan Barat di dalam memanfaatkan festival Gawai Dayak sebagai sarana untuk meningkatkan kunjungan wisatawan mancanegara. Bagaimana langkahlangkah yang dapat dilakukan sehingga festival Gawai Dayak mampu menjadi sarana meningkatkan jumlah kunjungan wisatawan asing ke Kalimantan Barat? Menggunakan metode deskriptif dengan pendekatan kualitatif, data yang dianalisis dalam artikel ini dikumpulkan melalui wawancara dan studi dokumentasi yang terkait dengan penyelenggaraan Gawai Dayak. Sejumlah upaya yang dilakukan pemerintah dalam membenahi tata kelola wisata di Kalimantan Barat teridentifikasi dan berpotensi menjadi instrumen soft power memperkenalkan budaya dan sekaligus menjadi sarana daya tarik wisata bagi Provinsi Kalimantan Barat.
\end{abstract}

Kata Kunci: Gawai Dayak, pariwisata, soft power

Gawai Dayak is an annual festival in West Kalimantan, Indonesia and Sarawak, Malaysia, which shows the richness of the arts and culture and traditions of the Dayak tribe that have developed both in West Kalimantan and in Sarawak. This article examines the efforts made by the West Kalimantan provincial government to utilize the Gawai Dayak festival as a means to increase foreign tourist visits. What steps can be taken so that the Gawai Dayak festival can be a means of increasing the number of foreign tourist visits to West Kalimantan? Using a descriptive method with a qualitative approach, the data analyzed in this article were collected through interviews and documentary studies related to organizing the Dayak Gawai event. A number of efforts made by the government in improving tourism management in West Kalimantan have been identified and have the potential to become a soft power instrument to introduce culture and at the same time become a means of tourist attraction for West Kalimantan Province.

Keywords: Gawai Dayak, tourism, soft power 
Masyarakat Kalimantan Barat memiliki beragam kekayaan seni budaya dan tradisi. Hal ini dibuktikan dengan berkembangnya berbagai acara pariwisata festival budaya di Kalimantan Barat. Berbagai acara terkait pariwisata tersebut merupakan bagian dari upaya meningkatkan mutu industri pariwisata di Kalimantan Barat. Langkah ini penting mengingat di kawasan Asia Tenggara, Indonesia sejauh ini berada pada peringkat ke-4 dengan kunjungan wisatawan asing (Kementerian Pariwisata Republik Indonesia 2015). Untuk menyukseskan hal tersebut maka tantangannya adalah bagaimana pemerintah, swasta, dan masyarakat dapat saling bersinergi.

Sejak tahun 2016, di Kalimantan Barat telah terjadi peningkatan arus masuk kunjungan wisatawan asing. Sebagaimana data yang tersaji pada Tabel 1, periode tiga tahun antara tahun 2016 sampai dengan tahun 2018 menunjukkan persentase peningkatan jumlah kunjungan wisatawan yang signifikan. Selain kombinasi dari berbagai faktor, peningkatan jumlah kunjungan wisatawan ini salah satunya diduga terkait dengan penyelenggaraan festival Gawai Dayak (Kompas 2019).

Tabel 1.

Jumlah Wisatawan Mancanegara ke Kalimantan Barat 2016-2018

\begin{tabular}{ccc}
\hline No. & Tahun & Jumlah Wisatawan Mancanegara \\
\hline 1. & 2016 & 32.261 orang \\
\hline 2. & 2017 & 58.492 orang \\
\hline 3. & 2018 & 70.578 orang \\
\hline
\end{tabular}

Sumber: Badan Pusat Statistik Provinsi Kalimantan Barat (2019)

Festival Gawai Dayak pertama kali diselenggarakan secara megah pada 25 September 1964, yang mana di dalamnya memuat unsur budaya suku Dayak yang mengandung nilai sosial untuk mengawal ketahanan pangan masyarakat. Melalui pelaksanaan Festival Gawai Dayak, masyarakat dapat melakukan panen setiap dua hingga tiga kali dalam setahun (Hi Pontianak 2019). Selain itu, karakteristik budaya yang unik dan menarik dari Suku 
Dayak, seperti penggunaan pakaian adat yang dipamerkan, lagulagu Dayak saat perayaan, serta pelaksanaan upacara ada, secara simultan menjadi daya tarik bagi wisatawan mancanegara.

Wisatawan yang berkunjung ke Kalimantan Barat tidak hanya berasal dari negara tetangga, tetapi juga dari benua lain. Marselina Soeryamassoeka, Bendahara Sekretariat Bersama Kesenian Dayak Kalimantan Barat, menginformasikan kepada penulis melalui wawancara pada 4 Oktober 2019 bahwa wisatawan yang berkunjung ke Kalimantan Barat datang dari berbagai kawasan.

\begin{abstract}
"Wisatawan asing yang paling banyak itu dari negara Malaysia tiap tahunnya bisa mencapai 300-500 pengunjung. Kemudian Amerika Serikat Suku Indian, Suku Maori, Selandia Baru, Jepang, China dan lain-lain. Ada juga dari Amerika yaitu suku Indian pernah datang sekitar 75 orang kemudian dari suku Maori dari Selandia Baru kemudian suku Aborigin dari negara Australia juga pernah datang kemudian dari suku Naga kemudian juga dari Madagaskar kemudian dari Jepang, Belanda, dan Afrika Selatan juga pernah ikut dalam kegiatan Gawai Dayak yang dilaksanakan di Kalimantan Barat.”
\end{abstract}

Beberapa kajian telah dilakukan terkait aspek-aspek terkait Festival Gawai Dayak. Handayani (2011) menyatakan bahwa bagi masyarakat suku Dayak di kota Pontianak, penyelenggaraan festival sebagai representasi acara kebudayaan suku Dayak. Kajian lain oleh Fusnika dan Dua (2019) tentang Gawai Dayak di suku Dayak Mualang menemukan bahwa penyelenggaraan Gawai Dayak adalah cermin upaya pelestarian budaya yang mampu mengajak Generasi Z untuk lebih peka dan meningkatkan persatuan pada masyarakat suku Dayak Mualang.

Berbeda dengan kajian sebelumnya, artikel ini menempatkan Festival Gawai Dayak dalam konteks soft power. Penulis berpendapat bahwa Festival Gawai Dayak mampu menjadi sarana soft power dalam meningkatkan kunjungan wisatawan mancanegara. Dengan mengusung konsep soft power sebagai power by attraction sebagaimana dikemukakan Joseph Nye (2004), penulis melihat bahwa Gawai Dayak dapat berperan sebagai sarana memikat perhatian publik asing melalui nilai-nilai budaya yang ada di dalamnya. 
Metode penelitian merupakan deskriptif dengan pendekatan kualitatif, yang mengambil Kota Pontianak sebagai lokasi penelitian. Sebagai sumber data yaitu dari Badan Kesatuan Bangsa dan Politik Kota Pontianak, Dinas Kepemudaan, Olahraga, dan Pariwisata Kalimantan Barat, Ketua Panitia Gawai Dayak Kota Pontianak, dan Sekretariat Bersama Kesenian Dayak Kalimantan Barat yang di mana peneliti melakukan wawancara kepada narasumber. Studi dokumentasi dilakukan dengan mengumpulkan literatur yang berkaitan dengan terkait peningkatan kunjungan wisatawan melalui event wisata Gawai Dayak.

\section{Pariwisata dan Soft Power}

Menurut Can-Seng Ooi (2015), setidaknya ada empat cara yang saling terkait dalam memandang pariwisata dan soft power. Pertama, wisatawan akan mengembangkan pemahaman yang lebih dalam tentang destinasi, yang sering kali mengarah pada empati yang lebih besar terhadap tempat tersebut. Empati itu diterjemahkan menjadi keakraban dan kesukaan pada tempat tersebut. Kedua, otoritas pariwisata bertugas untuk menampilkan citra negara yang menarik kepada dunia. Pesan-pesan tersebut dimaksudkan untuk memuliakan dan meningkatkan daya tarik destinasi sekaligus melawan citra negatif. Branding destinasi menjadi taktik soft power yang efektif. Ketiga, acara-acara besar juga penting dalam membangun pengaruh geopolitik karena acara-acara tersebut menarik wisatawan, menunjukkan kondisi dan lokasi destinasi, dan mengkomunikasikan kemampuan apa yang dimiliki oleh destinasi tersebut. Keempat, warga negara yang menjadi wisatawan di tempat lain akan mengirimkan pesan tentang negara asal mereka.

Konsep tentang soft power meliputi rasa hormat, ketertarikan, kemurahan hati (Nye 2008). Soft power merupakan salah satu unsur dari sebuah negara untuk mendorong atau mempromosikan atau memperlihatkan negaranya tersebut agar dipandang khalayak asing (Cull 2009). Saat ini kekuatan nasional dalam soft power telah diubah sehingga memiliki pendekatan baru terhadap kekuasaan dan perannya yang berubah dalam politik dunia (Gallarotti 2011). Awalnya soft power didefinisikan sebagai oposisi terhadap kekuatan keras (hard power) yang berupa paksaan 
fisik dan ekonomi. Soft power kemudian berevolusi dari waktu ke waktu secara teoretis sesuai kebutuhan berbagai kepentingan atau tempat (Angey-Sentuc \& Molho 2015). Soft power berkaitan dengan diplomasi publik karena diplomasi publik merupakan salah satu cara untuk meningkatkan soft power. Istilah "diplomasi publik" saat ini dipahami sebagai proses yang bersatu dan terpadu dengan penerapan yang lebih luas dan pandangan jangka panjang daripada propaganda masa perang (Chahine 2010). Dalam kaitan ini, Festival Gawai Dayak dapat dikategorikan sebagai diplomasi publik mengingat acara ini dihadiri oleh wisatawan mancanegara.

Soft power dengan unsur dan nilai budaya seperti Gawai Dayak akan dapat lebih efektif untuk menguatkan diplomasi suatu negara yang membutuhkan kesabaran dan kerja keras yang lebih besar (Amirbek \& Ydyrys 2014). Upacara Gawai Dayak merupakan puncak dari ungkapan rasa syukur kepada Jubata atau Tuhan (König 2016). Dalam kaitan dengan itu, penulis menawarkan formula pada Gambar 1 sebagai upaya sinergis untuk menjadikan Gawai Dayak sebagai instrumen soft power yang potensial menjadi sarana menarik kunjungan wisatawan asing ke Provinsi Kalimantan Barat.

\section{Gambar 1.}

Soft Power dan Gawai Dayak

\section{Soft Power Melalui Gawai Dayak}

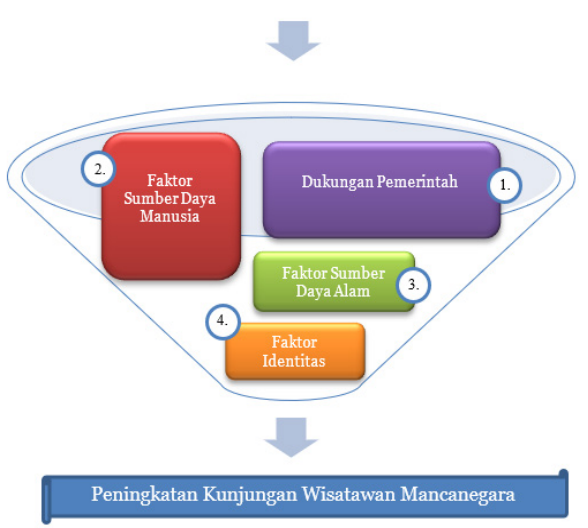

Sumber: Diolah oleh peneliti (2019) 


\section{Peran Pemerintah}

Kunjungan wisatawan ke Kalimantan Barat mendapatkan dukungan dari pemerintah yang diperkuat oleh keikutsertaan masyarakat (Dewi \& Issundari 2016). Untuk meningkatkan kunjungan wisatawan mancanegara selain dengan dukungan pemerintah dan peran serta masyarakat, terdapat upaya penguatan faktor sumber daya alam dan faktor identitas. Pada pelaksanaan Festival Gawai Dayak pemerintah daerah setempat selalu memberikan dukungan baik material maupun moril. Festival Gawai Dayak juga telah masuk ke dalam kalender acara pariwisata budaya tahunan daerah dan dalam Festival Gawai Dayak juga bisa menjadi peluang pemerintah daerah dalam meningkatkan pendapatan daerah. Hal tersebut memberikan efek ganda yang memerlukan pengelolaan fasilitas oleh pemerintah.

Berdasarkan wawancara dengan Marselina Soeryamassoeka, pada 4 Oktober 2019 mengatakan:

"Seperti kita saksikan bersama di setiap tahunnya, Pekan Gawai Dayak selalu dilaksanakan dengan meriah, menggunakan sarana umum, dan mengundang perhatian sendiri oleh masyarakat. Tentunya Pekan Gawai Dayak ini mendapatkan dukungan penuh oleh pemerintah provinsi maupun pemerintah daerah baik secara materil dan formil. Dengan harapan, Pekan Gawai Dayak ini dapat menjadi momen persatuan suku Dayak, juga masyarakat Kalimantan Barat. Kemudian bagaimana kebijakan pemerintah tentang gawai dayak ini tentunya telah dinaungi oleh dinas pendidikan dan budaya Provinsi Kalimantan Barat."

Melalui dukungan pemerintah, Festival Gawai Dayak telah memberikan peluang kepada banyak masyarakat agar bisa lebih terdorong lagi untuk menciptakan sesuatu yang menarik pengunjung. Hal tersebut ialah seperti pada pakaian adat Dayak yang setiap tahunnya untuk dipamerkan dalam acara Festival Gawai Dayak yang dapat menciptakan peluang untuk meningkatkan pendapatan perekonomian masyarakat. Dalam perayaan Gawai Dayak terdapat berbagai macam hal yang menarik misalnya diadakan lomba permainan, parade budaya, pakaian 
tradisional, hingga tradisi tato. Budaya-budaya yang ada pada Gawai Dayak tersebut merupakan identitas masyarakat setempat yang membuat tertarik wisatawan untuk datang menyaksikan secara langsung.

Berdasarkan wawancara dengan Alexander Rombonang, tanggal 3 September 2019, disebutkan bahwa:

“...dari tahun ke tahun terdapat perbaikan pada penyelenggaraan Gawai Dayak walaupun tetap masih ada kekurangan. Jika dulu skalanya kecil hanya masyarakat Kalimantan Barat, sekarang sudah mulai ada juga masyarakat Dayak di provinsi lain. Bahkan tahun yang lalu dari Malaysia dan Brunei juga datang. Tidak hanya hadir meramaikan namun juga ikut ambil bagian dalam itu. Bahkan ada etnis tertentu yang mirip-mirip Dayak Aborigin di Australia yang pernah ikut meramaikan atraksi dan berpartisipasi juga."

Dengan demikian, skala penyelenggaraan Gawai Dayak ini sudah bukan hanya di skala nasional dan regional, tapi sudah berada pada skala internasional. Oleh sebab itu, kemasannya yang disuguhkan pada penyelenggaraannya dari waktu ke waktu harus dikemas dengan lebih baik lagi.

Berdasarkan wawancara dengan Marsiana Rika dari Dinas Kepemudaan, Olahraga, dan Pariwisata Kalimantan Barat pada 4 Oktober 2019, wisatawan datang ke Kalimantan Barat khususnya dalam rangka Festival Gawai Dayak yaitu dikarenakan adanya budaya yang unik dan menarik, pakaian adat yang dipamerkan saat Gawai, lagu-lagu Dayak saat perayaan, serta keunikan yang paling penting bagi wisatawan asing yaitu saat pelaksanaan upacara adat. Atraksi tersebut salah satunya ialah Tarian Selamat Datang pada gambar di bawah. 


\section{Gambar 2.}

Tari Selamat Datang pada Pekan Gawai Dayak di Pontianak Tahun 2019

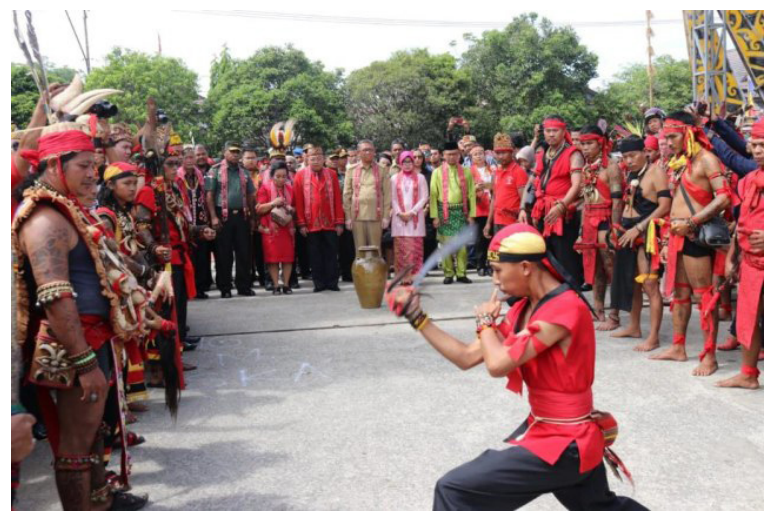

Sumber: Hi Pontianak (2019)

Seiringnya berganti kepemimpinan daerah Kalimantan Barat yaitu Bapak Cornelis, membuat semakin besar keinginan membuat festival itu menjadi sesuatu yang besar dan menjadikan sesuatu kebanggaan seluruh masyarakat Kalimantan Barat. Diharapkan bahwa peristiwa tersebut bukan hanya dinikmati oleh etnis Dayak saja, tetapi bisa menjadikannya kegiatan budaya yang bisa memberikan manfaat ekonomis. Selain Gawai Dayak festival, budaya lain yang dikembangkan adalah Cap Go Meh dan perayaan Robo-Robo yang menjadi kekayaan pariwisata Kalimantan Barat dan Indonesia.

\section{Faktor Sumber Daya Manusia}

Mengelola Gawai Dayak sekarang ini sudah ada melalui wadah Sekretariat Bersama Kesenian Dayak (Sekberkesda) yang berisi orang-orang yang menguasai bidangnya, walaupun hanya berjumlah 3-5 orang saja. Pemerintah melibatkan tenaga pendukung yang berasal dari anak-anak muda putra daerah. Sumber daya manusia pada Gawai Dayak ini cukup mumpuni sebab mereka memang pekerja budaya yang berasal dari unsur pegiat teater, pemusik, dan penari. Selain itu terdapat pula jurijuri pada lomba dan kompetisi yang diselenggarakan. 
Gawai Dayak dan acara adat dari suku Dayak dahulu identik dengan membuat persembahan, membunuh babi, dan semacamnya yang saat ini dapat dilakukan modifikasi tanpa menghilangkan nilai dari tradisinya. Hal tersebut serupa seperti pada saat Indonesia masih belum merdeka, terdapat kebiasaan ngayau atau bekayau. Bekayau itu kita sesama masyarakat Dayak saling menganggap orang lain itu musuh, sehingga dia harus bisa mengalahkan orang lain. Salah satu ukuran seseorang itu dianggap hebat, dianggap punya suatu kharisma apabila dia sudah bisa menunjukkan bukti membawa kepala. Seiring berjalannya zaman dan majunya peradaban, seluruh masyarakat Dayak kemudian bergabung sehingga tradisi tersebut tidak dilanjutkan.

Ritual Gawai Dayak tidak lepas dari budaya yang dianut masyarakat Dayak. Budaya corak yang unik dan ilmu kebatinan sangat kental dan terasa saat mengikuti ritual ini. Corak budaya yang bersahabat dengan alam, ciri khas nyanyian, tarian, hingga mantra selalu ada saat ritual dilakukan. Adanya ritual ini dapat mendorong pelestarian budaya Dayak yang menggambarkan cara hidup masyarakat Dayak yang terkenal dengan ketaatan adat istiadatnya (Herlina dkk. 2016). Wisatawan mancanegara datang untuk menyaksikan Gawai Dayak dan khususnya mereka yang tertarik dengan seni adat Dayak. Wisatawan dapat melihat dan merasakan Gawai Dayak secara langsung selagi mereka hadir sesuai dengan prosedur yang diadakan oleh panitia pelaksana. Gawai Dayak merupakan agenda pariwisata dan dari suku Dayak yang sarat dengan identitas di dalamnya dengan tujuan untuk mempertahankan eksistensi masyarakat Suku Dayak.

Berdasarkan wawancara dengan Alexander Rombonang, Kepala Badan Kesatuan Bangsa dan Politik pada tanggal 3 September 2019, dijelaskan bahwa:

"Berbicara mengenai kebersamaan, itu yang kemarin baru saja diperingati pertemuan masyarakat Dayak se-Kalimantan Barat di Tumbang anoi, sudah sekian ratus tahun yang lalu. Di situ masyarakat Dayak sudah bersepakat kebiasaan mengayau, bekayau atau yang namanya menggal kepala sudah diakhiri. Ke depannya kemudian perlu cari lagi cara-cara yang bisa diterima oleh semua pihak. Kita mempersiapkan sumber daya 
kita, manusia-manusia kita supaya menjadi lebih maju dan beradab serta bisa dinikmati. Gawai Dayak memberi dampak positif pada perekonomian masyarakat. Contohnya setiap $\mathrm{H}-5$ samapai $\mathrm{H}+5$ penyelenggaraan Gawai Dayak, semua penginapan sudah penuh. Biasanya begitu hunian hotel biasanya rata-rata di atas 90\% dan tentu saja dengan banyak masyarakat yang datang akomodasi dan konsumsi dan sebagainya dan masyarakat yang bergerak di arah itu medapat peluang untuk meraih pendapatan dan meraih keuntungan dan sebagainya."

Berdasarkan wawancara tersebut, terlihat bahwa event Gawai Dayak dapat menanamkan dan memperkuat nilai-nilai budaya yang juga memperkuat soft power Indonesia. Selain itu juga terdapat penguatan norma sosial, falsafah sosial masyarakat Dayak melalui event Gawai Dayak ini (Atok 2020). Filosofi Gawai Dayak menggambarkan interaksi sosial melalui gotong-royong yang luar biasa hidup kebersamaan. Interaksi sosial biasanya terjadi karena setiap aktor yang terlibat di dalamnya menafsirkan makna dalam setiap tindakannya (Randa dkk. 2011). Untuk itu masyarakat perlu disiapkan agar tidak hanya terpenjara dengan tradisi-tradisi lama. Seiring dengan berubahnya pola yang dulu identik sekali dengan pola pertanian yang berpindah-pindah, sehingga panen sekali setahun.

\section{Faktor Sumber Daya Alam}

Faktor ini telah digunakan sebagai aset soft power untuk menarik wisatawan melihat Festival Gawai Dayak. Hal ini dikarenakan faktor sumber daya alam seperti rotan, manik-manik, kulit kayu digunakan sebagai bahan untuk atraksi Gawai Dayak. Selain itu terdapat bulu burung, bambu, rotan, kemudian serat benang nanas untuk menganyam manik, kulit kayu digunakan untuk baju ataupun dekorasi Gawai Dayak.

Berdasarkan wawancara dengan Ketua Panitia Festival Gawai Dayak Kota Pontianak pada 4 Oktober 2019 menyatakan bahwa:

"Masyarakat Dayak sangat antusias dalam menyambut event Pekan Gawai Dayak ini. Masyarakat siap baik dalam tenaga, materi, juga pemikiran yang diberikan untuk menyukseskan Pekan Gawai Dayak ini. Dalam kegiatan 
Gawai Dayak tiap tahunnya, Rumah Radakng menjadi objek utama wisatawan. Dan untuk kegiatan pekan gawai Dayak tiap tahunnya tidak begitu berbeda, kegiatan yang dilaksanakan antara lain upacara adat, lagu Dayak, lomba kesenian dan busana Dayak, permainan adat, long march, melukis, menganyam, sumpit, menumbuk padi, lomba tato, dan lainnya."

Hal-hal tersebut bisa menjadi salah satu kenangan bagi wisatawan, sebagai poin Sapta Pesona pariwisata Indonesia. Objek dan kegiatan yang ditawarkan tadi merupakan keunikan yang hanya dapat ditemukan di Festival Gawai Dayak. Hal ini yang kemudian mengundang antusias para wisatawan asing untuk melihat bahkan turut berpartisipasi di dalam Gawai tersebut.

Faktor alam telah menjadi salah satu destinasi penunjang. Wisatawan yang datang ke Kalimantan Barat untuk melihat Festival Gawai Dayak, mereka sekaligus berekreasi dan berwisata ke objek wisata lain yang ada di sekitarnya. Generasi terdahulu percaya bahwa alam akan marah jika proses Gawai tidak dilaksanakan secara benar. Oleh karena itu Gawai selalu sarat dengan ritual, mohon ijin dari Yang Kuasa dengan melakukan sesajen pada awal Gawai. Para wisatawan asing sangat tertarik dengan unsur magis yang terdapat dalam Gawai Dayak karena ada ritual dan telah memberikan peningkatan pengetahuan mereka tentang ritualisasi Gawai Dayak. Hal ini searah dengan wawancara dengan wisatawan asal Aborigin, James, tanggal 25 Mei 2019 menyatakan, "I am very interested in the magical rituals of the Dayak. I think about performing the ritual from start to finish".

Festival Gawai Dayak adalah bagian dari kepercayaan nenek moyang yang dapat dilestarikan karena merupakan penghargaan terhadap nenek moyang. Makna lain adalah perlindungan terhadap alam. Alam tidak boleh dirusak tanpa tujuan yang jelas, mendoakan agar tanah subur, tidak ada gangguan hama pada tanaman panen dan sebagainya. Semua ini disampaikan melalui upacara ritual nyanyian "lemambang". Gawai Dayak memiliki kekuatan magis yang membuat setiap orang tertarik untuk berkumpul dan bertemu. Selain itu, Gawai Dayak juga dapat memeriahkan dan mempererat hubungan masyarakat Dayak. Singkatnya, Gawai Dayak adalah media untuk menghibur 
masyarakat dapat meningkatkan komunikasi masyarakat yang melibatkan diri dalam acara tersebut (Atok 2017; Atok 2020).

Hambatan utama dalam potensi ini untuk meningkatkan kunjungan wisatawan mancanegara salah satunya adalah sektor infrastruktur. Fasilitas penginapan, infrastruktur, dan transportasi pada objek wisata di Kalimantan Barat masih sangat terbatas. Banyak sekali kekayaan alam Kalimantan Barat yang luar biasa namun masih kurang didukung oleh sarana dan prasarana sehingga untuk membangkitkan itu diperlukan biaya besar. Namun demikian, poin kenangan dalam Sapta Pesona melalui event ini menjadi sarana promosi bagi pariwisata Kalimantan Barat dalam menambah jumlah wisatawan mancanegara pada tahun berikutnya.

\section{Faktor Identitas}

Identitas menjadi faktor penting dalam kaitannya dengan keberadaan suku-suku di Indonesia. Suku Dayak memiliki 400 sub suku yang hidup di seluruh pulau Kalimantan yang semuanya memiliki tradisi Gawai (Darmadi 2016), dan tradisi ini merupakan identitas yang ingin dilestarikan oleh suku Dayak. Gawai Dayak menampilkan acara utama yaitu nyangahathn atau pengajian mantra (Ivo 2012). Selain itu, objek dan kegiatan yang ditawarkan pada acara Gawai Dayak terdiri dari berbagai macam seni pertunjukan yang menunjukkan budayanya, perlombaan berarti setiap daerah yang mengikuti perlombaan untuk menampilkan keahliannya dalam perlombaan yang ditawarkan contohnya lomba gasing dan menyumpit. Gawai merupakan sarana melestarikan budaya leluhur dan menumbuhkan rasa solidaritas di tengah masyarakat Dayak.

Pada event Gawai Dayak ini, objek dan kegiatan yang sering ditawarkan dalam gawai Dayak lebih banyak objek kesenian, yaitu sekitar 70\% dan tradisi hanya sekitar 30\% saja. Objek yang ditawarkan dalam gawai Dayak adalah menampilkan budaya Dayak. Terdapat perbedaan antara gawai Dayak di Kota Pontianak dan di kampung-kampung. Di Kota Pontianak, Gawai Dayak 
diselenggarakan berupa festival budaya. Sementara di kampungkampung Gawai Dayak diadakan dalam bentuk upacara bersyukur. Pada acara ini masyarakat mengadakan makan-makan besar di tiap rumah yang mengadakan gawai. Wisatawan asing yang hadir kebanyakan tertarik dengan permainan adat yaitu sumpit. Sebab dalam permainannya mengundang keseruan tersendiri. Selain itu pergelaran seni juga menjadi agenda yang paling banyak diminati oleh wisatawan nusantara maupun internasional. Di samping menonton wisata kuliner juga bisa melibatkan diri dalam eventevent seperti atraksi kesenian dan kebudayaan.

Bagi banyak negara di dunia, sektor pariwisata merupakan pendorong penting pembangunan ekonomi (Otrachshenko \& Nunes 2019). Daya tarik wisata pada Gawai Dayak berkaitan dengan tradisi terutama ladang. Potensi Gawai Dayak berkaitan dengan usaha masyarakat (petani), larangan dalam membakar ladang menjadi hal yang sangat serius karena akan berdampak pada alam dikemudian harinya sehingga dapat mengurangi potensi alam yang ada. Melalui Gawai, masyarakat Dayak kini dapat mempelajari kearifan lokal dan nilai-nilai kehidupan. Gawai menghubungkan generasi lampau dan generasi sekarang (Darmadi 2017).

Gawai Dayak sesungguhnya merupakan suatu bentuk ungkapan rasa syukur. Selain itu, Gawai Dayak menjadi acara tahunan yang paling ditunggu di Pontianak. Di Malaysia, Gawai Dayak menjadi hari libur resmi bagi suku Dayak, dan pertama kali diadakan secara besar-besaran pada tanggal 25 September 1964 (bin Haji Ishak 2010). Banyak yang dapat dipertunjukkan pada saat Gawai Dayak tersebut dari berbagai kabupaten atau sanggar- sanggar yang ada. Seni budaya dan tradisi yang terkandung dalam Gawai Dayak sebagai potensinya untuk menarik wisatawan asing di antaranya yaitu tari-tarian, nyanyian, sumpit, seni bercocok tanam, dan berbagai permainan tradisional, seni suara, seni musik, karawitan, pahatan, merangkai manik-manik dan berbagai macam lainnya. Salah satunya adalah seperti membuat manik-manik yang bisa dibuat dengan bentuk seperti gelang, topi dan lainnya. Juga terdapat pertunjukan menenun dengan menggunakan alat tradisional. Biasanya akan ada orang-orang yang bisa menenun dan pengunjung dapat mengamatinya sendiri cara pembuatannya 
serta dapat melihat hasil-hasil yang sudah jadi. Di samping itu kita juga dapat menikmatinya dengan bisa memilikinya atau membeli hasil yang sudah ada.

Selain itu juga terdapat atraksi yang menampilkan budaya seperti tato dengan cara yang lebih modern tapi tidak meninggalkan nilai tradisionalnya. Tato yang biasanya hanya bisa ditempel saja atau hanya dalam berbagai bentuk tato lainnya, tetapi pada acara ini akan memperlihatkan tato asli khas Dayak. Hal ini menjadi salah satu cara untuk mempromosikan wisata Kalimantan Barat khususnya pada kebudayaan Dayak.

Filosofi tato memiliki variasi yang luas. Kategori utamanya ialah memiliki nilai terkait identitas pribadi, milik suatu kelompok atau budaya, dan estetika (Csesznek \& Stemate 2019). Bagi masyarakat suku Dayak, tato bukan hanya seni melukis gambar di atas tubuh saja melainkan juga memiliki makna filosofis yang sangat dalam serta identitas yang harus mereka jaga. Setiap pola dan bentuknya memiliki makna salah satunya ialah sebagai pelindung dari roh yang jahat agar tidak mengganggu atau masuk ke dalam badan. Pemakaian tato tidak bisa dipakai asal-asalan oleh sembarang orang sebab ada ritual yang harus dilakukan untuk membuatnya dan harus bertanggungjawab selama menggunakan tato tersebut (Detik, 2020). Potensi identitas pada tradisi yang ada dalam Gawai Dayak ini kemudian menarik bagi wisatawan untuk menyaksikannya sehingga mendatangkan lebih banyak wisatawan mancanegara.

\section{Simpulan}

Penelitian ini menemukan bahwa peningkatan kunjungan wisatawan mancanegara melalui Gawai Dayak didukung melalui upaya-upaya sebagai berikut. Pertama, melalui dukungan pemerintah (peran pemerintah dalam pengembangan Gawai Dayak sebagai potensi wisata). Pemerintah setempat selalu memberikan dukungan baik material maupun moril ataupun kebijakan pada pelaksanaan Gawai Dayak sebab event tersebut memberikan efek yang memerlukan pengelolaan fasilitas oleh pemerintah untuk 
lebih supaya semakin terarah dan lebih baik semakin dinamis satu ke waktu lain. Kedua, melalui peran masyarakat, yaitu melalui penguatan sumber daya manusia sebagai pendukung kegiatan Gawai Dayak. Sumber daya manusia dalam mengelola Gawai Dayak sekarang ini sudah ada wadah yaitu Sekretariat Bersama Kesenian Dayak (Sekberkesda) yang berisi orang-orang yang menguasai bidangnya. Sumber daya manusia tersebutlah yang kemudian menjaga dan melestarikan event Gawai Dayak ini. Ketiga, faktor sumber daya alam. Festival Gawai Dayak secara tidak langsung berkaitan erat dengan alam karena Festival gawai Dayak ini membicarakan tentang budaya dan syukur kepada Jubata (Tuhan). Alam juga menjadi salah satu destinasi yang menarik penunjang. Wisatawan mancanegara yang datang ke Kalimantan Barat untuk melihat Festival Gawai Dayak, mereka sekaligus berekreasi dan berwisata ke objek wisata lain yang ada di sekitarnya. Keempat, melalui terdapat faktor identitas yang perlu dilestarikan. Tradisi dengan berciri khas identitas masyarakat Dayak pada Gawai Dayak seperti tato, manik, nyangahathn, dan sebagainya menarik untuk disaksikan sehingga mendatangkan lebih banyak wisatawan mancanegara. Temuan penelitian ini menunjukkan bahwa event Gawai Dayak sebagai event tradisi lokal dengan keunikannya dapat menyokong soft power Indonesia di forum internasional. Hasil dari penelitian ini berkontribusi pada pengembangan kajian soft power melalui pariwisata serta memperkaya khazanah kajian hubungan internasional.

\section{Referensi}

\section{Buku dan Bab dalam Buku}

Can-Seng Ooi, 2015. "Soft power, tourism", dalam J. Jafari, H. Xiao (ed.). 2015. Encyclopedia of Tourism

Cull, Nicholas. John. 2009. Public diplomacy: Lessons from the past. No s 12. Los Angeles, CA: Figueroa Press.

Nye, Joseph S. 2004. Soft Power the Means to Success in World Politics. USA: Public Affairs. 
Yavuzaslan, Kiymet, and Murat Cetin. 2016. "Soft Power Concept and Soft Power Indexes." dalam Business Challenges in the Changing Economic Landscape-Vol. 1, hal. 395-409. Springer, Cham.

\section{Jurnal dan Jurnal Daring}

Amirbek, Aidarbek., \& Kanat Ydyrys. 2014. "Education and Soft Power: Analysis as an Instrument of Foreign Policy." Procedia - Social and Behavioral Sciences, 143, 514-516.

Angey-Sentuc, Gabriele., \& Jeremy Molho. 2015. "A Critical Approach to Soft Power: Grasping Contemporary Turkey's Influence in The World." European Journal of Turkish Studies, 21.

Atok, Kristianus. 2017. "Dialektika Budaya Dayak: Enkulturasi Agama Katolik dengan Budaya Dayak Kayaan." Anımage Jurnal Studi Kultural 2, (2): 87-93.

Atok, Kristianus. 2020. "Gawai Dayak as Communication Media of Dayak People in Borneo.” MEDIO 2 (1): 26-36.

bin Haji Ishak, Mohd. Sulaimi. 2010. "Cultural and Religious Festivals: The Malaysian Experience." JATI : Journal of Southeast Asian Studies, 15, 97-111.

Csesznek, C., \& Stemate, D. 2019. “Tattoos As a Form of Expressing Identity and Perceptions of the Health Risks of Getting Tattooed." Bulletin of the Transilvania University of Braşov Series VII: Social Sciences - Law, 12 (61): 59-70.

Darmadi, Hamid. 2016. "Dayak Asal-Usul dan Penyebarannya di Bumi Borneo (1)." Sosial Horizon, 3 (2): 322-340.

Darmadi, Hamid. 2017. "Dayak and Their Daily Life." JETL (Journal Of Education, Teaching and Learning), 2 (1): 101.

Dewi, Machya A., \& Sri Issundari. 2016. "Desa Wisata sebagai Aset Soft Power Indonesia." Masyarakat, Kebudayaan Dan Politik, 29 (2): 68. 
Fusnika, \& Falentina. L. Dua. 2019. "Kontribusi Budaya Lokal Gawai Dalam Menumbuhkan Nilai Solidaritas Generasi Z Pada Suku Dayak Mualang." Jurnal Pekan (Pendidikan Kewarganegaraan), 4 (2): 149-158.

Gallarotti, Giulio. M. 2011. "Soft Power: What It Is, Why It's Important, And The Conditions For Its Effective Use." Journal of Political Power, 4 (1): 25-47.

Ivo, Herman. 2012. "Gawai Dayak dan Fanatisme Rumah Panjang Sebagai Penelusuran Identitas.” Jurnal Humaniora, 13 (3): 292-298.

König, Anika. 2016. "Identity Constructions and Dayak Ethnic Strife in West Kalimantan, Indonesia." Asia Pacific Journal of Anthropology, 17 (2): 121-137.

Nye, Joseph. S. 2008. "Public Diplomacy and Soft Power." Annals of the American Academy of Political and Social Science, 616 (1): 94-109.

Otrachshenko, Vladimir., \& Luis C. Nunes. 2019. "Fire Takes No Vacation: Impact of Fires on Tourism." SSRN Electronic Journal.

Randa, Fransiskus, Iwan Triyuwono, Unti Ludigdo, and Eko Ganis Sukoharsono. 2011. "Studi Etnografi Akuntabilitas Spiritual pada Organisasi Gereja Katolik yang Terinkulturasi Budaya Lokal.” Jurnal Akuntansi Multiparadigma 2 (1): 35-51.

\section{Artikel Daring}

Detik. 2020. "Tato Dayak Aruk, Wujud Keindahan dan Filosofi Perjalanan.” [daring] https://20.detik.com/tapalbatas/20201216-201216119/tato-dayak-aruk-wujudkeindahan-dan-filosofi-perjalanan

Hi Pontianak. 2019. "Gawai Dayak, Cara Masyarakat Bersyukur atas Pangan Berlimpah." Kumparan. [daring] https:// kumparan.com/hipontianak/gawai-dayak-cara-masyarakatbersyukur-atas-pangan-berlimpah-1r7DgjN7mck/full 
Kompas 2019. "Pekan Gawai Dayak Ke-34 dibuka upaya genjot kunjungan wisatawan." [daring] https://travel.kompas.com/ read/2019/05/21/120000427/pekan-gawai-davak-ke-34-dibukaupaya-genjot-kunjungan-wisatawan-?page=all

\section{Dokumen Resmi Pemerintah}

Badan Pusat Statistik Provinsi Kalimantan Barat. 2019. "Provinsi Kalimantan Barat dalam Angka 2019." [daring] https://kalbar.bps.go.id/ publication/2019/o8/16/5bfa1ecd5bocf472e92cc114/ provinsi-kalimantan-barat-dalam-angka-2019.html

Kementerian Pariwisata Republik Indonesia. 2015. "Renstra Kementerian Pariwisata 2015 - 2019." [daring] https://www. kemenparekraf.go.id/asset_admin/assets/uploads/media/ pdf/media_1564022917_RENSTRA_KEMENPAR_20152019_V_5(30_11_2015).pdf

\section{Lain-lain}

Chahine, Joumane. 2010. Public Diplomacy: A Conceptual Framework. Disertasi Doktor, McGill University.

Handayani, Lituhayu. 2011. "Makna Pekan Gawai Dayak di Pontianak bagi Masyarakat Dayak Kalimantan Barat" [daring] https://digilib.uns.ac.id/dokumen/detail/18970/Makna-PekanGawai-Dayak-Di-Pontianak-Bagi-Masyarakat-Dayak-KalimantanBarat

Herlina, Herlina, Andayani, Herman J. Waluyo, \& Budhi Setiawan. 2016. "Perspective Literature In Ritual Gawai Dayak Literature Teaching Materials As Regional College.” Dalam Proceeding of the International Conference on Teacher Training and Education, vol. 2, no. 1, hal. 512-516. 
Elyta

Global Strategis, Th. 15, No. 1 
Gawai Dayak Festival and the Increase of Foreign Tourist Visits 